\title{
APPLYING THE HYBRID STRATEGY IN SOLVING MATHEMATICAL WORD PROBLEMS AT THE ELEMENTARY SCHOOL LEVEL
}

\author{
Siddiqah Rosli (iD, Masitah Shahrill (iD, Jamilah Yusof (iD) \\ Sultan Hassanal Bolkiah Institute of Education, Universiti Brunei Darussalam (Brunei Darussalam)
} 18h8390@ubd.edu.bn, masitah.shahrill@ubd.edu.bn, jamilah.yusof@ubd.edu.bn

Received Marc 2020

Accepted June 2020

\section{Abstract}

The study was designed to assess the effectiveness of an alternative teaching approach strategy called the Hybrid Strategy. It was intended specifically in minimising the common errors made by students, which were Comprehension and Transformation errors, and aimed at helping students to perceive word problems as a story line to be completed using the Hybrid Strategy. This strategy is a step-by-step guidance to improve students' visualisations and perceptions of mathematical word problems. The strategy incorporates the use of pictorial representations for students' visualisation and interrogative words (who, what, where, when and how) using the mnemonic Mr. How and his 4 Warriors to prompt students' understanding when solving 1-step and 2-step word problems. The study involved 39 Year 5 students from a local government school in the Brunei-Muara district of Brunei Darussalam. The four research instruments were used in collecting the data: diagnostic pre-test, diagnostic post-test, Newman's Error Analysis interviews and general observations during intervention lessons. Analyses from students' written test responses revealed that the students committed all five types of Newman error and the most common type of errors occurred in this study are Comprehension errors. Further analyses showed that the use of the Hybrid Strategy in minimising Comprehension and Transformation errors was successful. However, there was only a slight improvement of students' scores in their post-test, contributing to only a minor extent of the effectiveness of the Hybrid Strategy used in this study. Additionally, slight positive shifts of students' perceptions were observed towards solving mathematical word problems.

Keywords - Mathematics, Word problems, Hybrid strategy, Errors, Visual representations.

\section{To cite this article:}

Rosli, S., Shahrill, M., \& Yusof, J. (2020). Applying the hybrid strategy in solving mathematical word problems at the elementary school level. Journal of Technology and Science Education, 10(2), 216-230. https://doi.org/10.3926/jotse.965

\section{Introduction}

Mathematics is often seen as a bridge that links theories to real-life application. Demonstrating connections between Mathematics and real-life situations though everyday context is essential in the primary years of teaching and learning Mathematics (Thorton \& Statton, 2011). Thus, one way to build the foundation is through instilling fundamental skills in students for solving mathematical word problems. The use of representation is highly associated with mathematical word problems. Instructional 
procedures that incorporate visual representations have been studied and proven effective (Kingsdorf \& Krawec, 2016). Visual representations can be in the form of diagrams, vivid images and concrete objects that could help students in their understanding and making connections effectively in solving mathematical word problems.

In Brunei Darussalam, a teacher-dominated learning environment has always been observed in most primary schools (Abdullah., Shahrill, Yusof \& Prahmana, 2018; Shahrill, 2009). Hence, limiting the interactions and students' creativity in classrooms, which eventually causes a common difficulty faced by primary school students particularly in the area of understanding the proves involved in solving word problems in Mathematics. Furthermore, the importance of instilling strong mathematical conceptual understanding in students has been emphasised in previous studies (Baroudi, 2006; Pungut \& Shahrill, 2014; Shahrill, Prahmana \& Roslan, 2018, Shahrill, Putri, Zulkardi \& Prahmana, 2018; Chong, Shahrill, Putri \& Zulkardi, 2018; Abdullah, Shahrill, Tan \& Yusof, 2017). However, other studies mentioned that teachers are inclined towards finishing the syllabus than focusing on students' understanding, thus limiting to mere delivering of procedural knowledge than making connections to real-life situations (Abdullah et al., 2018; Shahrill, 2009; Shahrill, Prahmana et al., 2018, Shahrill, Putri et al. 2018; Chong et al., 2018; Rosney, 2008; Sakdiah, 2008; Shahrill, 2018; Shahrill \& Prahmana, 2018; Chong, Shahrill \& Li, 2019; Shahrill \& Clarke, 2019). Therefore, less realistic considerations and common sense are used in students' attempts to solve word problems (Verschaffel, Brian \& De Corte, 2000).

A study was conducted which revealed the most common types of errors committed by Year 6 Bruneian students in solving word problems were Comprehension and Transformation errors (Yusof, 2003; Saman \& Suffolk, 2001). At present, researchers have demonstrated high percentages of Comprehension, Transformation and Process skills errors (Newman, 1977), which are still proven persistent (White, 2009). Students have difficulties to comprehend word problems hence inhibiting them from being able to transform the sentences into an appropriate mathematical form (Newman, 1977, 1983). The high percentages of Comprehension, Transformation and Process skills errors are also evident in Bruneian students (Yusof \& Langkan, 2016). Therefore, this study intended to focus on improving students' understanding and perceptions of word problems particularly on Comprehension and Transformation stages of the Newman Procedure (Newman, 1977).

As specified by Sajadi, Amiripour and Malkhalifeh (2013), a word problem is essentially a story problem and generally, the students have to make connections between the known and the unknown. Results from studies conducted by previous researchers proved that students' perceptions towards mathematical word problems play a contributing factor in their ability to solve and understand word problems (Pungut \& Shahrill, 2014; Wong, Lam, Wong, Leung \& Mok, 2001; TESS, 2017). This is further supported by recent studies where it was reported that it is the attitude and experience of students towards Mathematics that determine their ability and level of engagement in solving word problems (Gebremichael, 2014; Uesaka, Manalo \& Ichikawa, 2007).

A further approach to address students' difficulties in solving mathematical word problems is by guiding them to perceive the word problems as story problems. This is supported by the Teacher Education through School-based Support in India or TESS, in which they encouraged the use of storytelling as a tool for understanding word problems. This way TESS believed that viewing word problems as story problems can assist students who experiences difficulties when trying to make sense the context of the word problems. Haury (2001) also believed that one way to connect school Mathematics to everyday life is by drawing attention to the Mathematics embedded in the literature of everyday life. The use of storytelling provokes students' interests (Welchman-Tischler, 1992) where eventually they will be able to create their own story context to fit the Mathematics. Storybooks can act as catalysts that can motivate students, ignites their interests and experiences and provide contexts that engage them (Hong, 1996). Both teachers' and students' creativity will also be stimulated as they are able to personalise Mathematics with the use of their imaginative powers through the use of storytelling (Schiro, 2004). This is further supported by Murphy (2000), where the storytelling can help students to connect 
mathematical ideas to personal experiences and accommodate different ways of learning. The connections established during learning result in a sense of belonging in Mathematics for the students (Toor \& Mgombelo, 2015).

Essentially, the Hybrid Strategy for solving mathematical word problems used in this study is an alternative teaching approach strategy and is specially designed and first introduced by the first author for this study. She decided to adapt the term Hybrid in naming the strategy designed specifically for this study, as the strategy originates from the hybridisation of drawing and perceiving word problems as story problems. Additionally, we believed that the use of either one of the strategies alone is not sufficient for students to understand the context used in word problems. Therefore, here and thereafter, the strategy used in this study is referred to as the Hybrid Strategy. The Hybrid Strategy used in this study is unique and only true to this study. Therefore, it could not be generalised beyond the scope of this study. The strategy is a step-by-step guidance to improve students' visualisations and perceptions of mathematical word problems. The strategy incorporates the use of pictorial representations for students' visualisation and interrogative words (who, what, where, when and how) using the mnemonic Mr. How and his 4 Warriors to prompt students' understanding when solving 1-step and 2-step word problems.

\section{Methodology}

This study adapted the Action Research approach. Action Research is defined as a systematic inquiry being conducted, for example by teacher researchers, principals, school counsellors or any other stakeholders that are involved in the teaching and learning environment to gather information on their students and the schools (Mills, 2014). The research is aimed at gaining insights, developing reflective practices and providing platforms for improvements in students' academic performances.

The focus sample for this study was 39 Year 5 students from a local government elementary school level in Brunei, who were already streamed into three levels of ability (refer to Table 1) according to their previous academic performance in Mathematics from their end of year examination that was taken the previous year. These students were grouped according to their level of ability in Mathematics.

\begin{tabular}{|l|r|}
\hline Ability & \multicolumn{2}{|c|}{ Total } \\
\hline Above Average & 14 \\
\hline Average & 16 \\
\hline Below Average & 9 \\
\hline Total & 39 \\
\hline
\end{tabular}

Table 1. Details of students' grouping

The pre-test paper on word problems in Mathematics prepared for the participants consisted of 10 essay-based questions on four basic arithmetical operations of Addition, Subtraction, Multiplication and Division. These questions were divided into two sections. The highest possible score for the pre-test is 25 . All scores were entered into a spreadsheet and the errors committed by the participants were recorded in the form of frequencies. The test was conducted in a usual classroom setting within a one-hour lesson period. As for the test paper, it was arranged with levels of difficulties in order to test the participants' prior knowledge and understanding. This was also used to identify the patterns and diagnose the errors committed by the participants.

The nature of the post-test is similar to that of the pre-test paper in terms of the arrangement of the questions. However, changes were made to the numerical figures and settings to each question. Subsequently, amendments were done after the analysis of the pre-test papers, to indicate the area(s) of focus on and to test the participants' understanding of the Hybrid Strategy delivered during the intervention lessons. 
Additionally, this study adapted the Newman's Error Analysis (NEA) (Newman, 1977) interview prompts along with some additional interview questions for further probing. Eleven "information rich" participants with verbal skills were selected for the interview (three or four students from each level of abilities). An audio recorder was utilised to capture the interview responses, which were then transcribed. The one-on-one interview sessions were conducted in the school computer laboratory during normal school hours according to the availability of the selected participants. As for the general observation, the first author had carried out an informal observation when the intervention lessons were conducted and she was also an active participant observer, collecting required data and paradoxes (if any) via field notes. Due to limited timeframe allocated in conducting this study, the intervention lessons were restricted to three sessions only in accordance to the Scheme of Work provided by the school. Hence, the first author carried out only one cycle of Action Research for this study.

\section{Results}

\subsection{Classification of Errors}

The students' errors were conducted first followed by categorising the types of error committed by the students based on the Newman's Error Analysis (NEA) (Newman, 1977). Newman identified the five basic errors, which were Reading, Comprehension, Transformation, Process Skills and Encoding (Newman, 1977). In this study, two more types of error were identified, which evidently occurred from students' pre- and post-tests; No working and/or no answer, for when there were no response given, thus leaving an empty space in the working and/or answer spaces provided, and Incomplete, this type of error only occurred in the 2-step word problem questions in this study where the students provided solution with an incomplete series of operations.

\subsection{Students' Written Responses from the Pre- and Post-Tests}

To find out the types of error that was committed by Year 5 students in solving word problems, students' written responses from the pre- and post-tests were first analysed using descriptive statistics to show the frequency distribution of identified errors that have occurred for 1-step and 2-step word problems from the pre- and post tests. The following Table 2 summarises the percentage means of types of error between the pre-test and post-test.

\begin{tabular}{|l|r|r|r|}
\hline Types of Errors & \multicolumn{1}{|c|}{ Pre-Test } & \multicolumn{1}{|c|}{ Post-Test } & \multicolumn{1}{c|}{ Percentage Difference } \\
\hline Comprehension & $49.1 \%$ & $36.7 \%$ & $+12.4 \%$ \\
\hline Transformation & $26.0 \%$ & $8.5 \%$ & $+17.5 \%$ \\
\hline Process skills & $10.7 \%$ & $15.0 \%$ & $-4.3 \%$ \\
\hline Encoding & $1.4 \%$ & $3.2 \%$ & $-1.8 \%$ \\
\hline No working and/or no answer & $4.4 \%$ & $27.8 \%$ & $-23.4 \%$ \\
\hline Incomplete & $16.7 \%$ & $17.7 \%$ & $-1.0 \%$ \\
\hline
\end{tabular}

Table 2. Percentage means of types of error in the pre- and the post-tests

From Table 2, Comprehension error has the highest percentage means compared to other types of error. This further emphasised that the most common type of error occurred in the pre- and post-tests of this study is Comprehension errors. The table also shows percentage means of Comprehension and Transformation errors decrease from the pre-test to the post-test with percentage difference of $+12.4 \%$ and $+17.5 \%$ respectively. This proves that the use of Hybrid Strategy in minimising those errors was successful. However, the percentage means of the other remaining types of error increase from the pre-test to the post-test, with No working and/ or no answer having the highest percentage difference of $-23.4 \%$, which reflects high degree of students' negligence in answering the questions in the post-test. Therefore, for this reason, the students' overall achievement in the post-test is lower than the pre-test. 


\subsection{Students' Interview Responses}

The one-on-one interview sessions were conducted after intervention lessons on 11 selected students based on their verbal skills. The structured interviews were adapted from Newman's Error Analysis (NEA) (Newman, 1977) interview prompts with a few additional questions related to the use of visualisation and the Hybrid Strategy. Interview transcripts of 11 selected students were analysed and excerpts from the transcripts are presented in this section for discussion. For analysis purposes, the code ' $\mathrm{I}$ ' represents the interviewer and 'S (followed by a number)' represents the student interviewed.

The first five questions of the interview focused on investigating students' thinking processes and the types of error they commit when solving a word problem presented during the interview. The word problems used during the interviews were adapted from the pre-test paper. For the purpose of extracting maximum possible information from the students and due to differences in levels of ability, each student was given a word problem suited to their level of competency. The last three questions of the interview were aimed at exploring their preferences on methods to solve mathematical word problems.

Interview responses to Question 1: Please read the question to me. If you don't know a word, leave it out. All of the students interviewed in this study demonstrated acceptable level of fluency in their reading. However, having the ability to read does not necessarily reflect understanding (Yusof \& Langkan, 2016). The interviewed students' level of comprehension is then analysed as follows.

Interview responses to Question 2: Tell me what the question is asking you to do. The interview excerpts from some of the selected students are presented in the following Tables 3 and 4.

\begin{tabular}{|l|l|}
\hline Speaker & Questions and Responses \\
\hline Interviewer & Please read the question to me, if you don't know a word, leave it out. \\
\hline S21 & $\begin{array}{l}\text { Nabilah make, bake } 6 \text { cake of a the same size, she divided the cake equally among her } 3 \text { friends, } \\
\text { how many cake... Did each friend receive? }\end{array}$ \\
\hline Interviewer & Ok, tell me what the question is asking you to do \\
\hline S21 & Uhhh...[After 8 seconds] uhh give equal among her friends? 3 friends? \\
\hline
\end{tabular}

Table 3. Interview excerpts from student S21

\begin{tabular}{|l|l|}
\hline Speaker & Questions and Responses \\
\hline Interviewer & Please read the question to me, if you don't know a word, just leave it out \\
\hline S39 & {$[$ S39 starts reading silently] } \\
\hline Interviewer & Ok can you read it first to me? \\
\hline S39 & A book cost \$9 each. Hadi bought 3 books. How much did he spend altogether? \\
\hline Interviewer & Ok, tell me what the question is asking you to do \\
\hline S39 & Umm add? \\
\hline
\end{tabular}

Table 4. Interview excerpts from student S39

The interview responses to Question 2 above show that the students were hesitant in responding to the question posed. These are highlighted in the last line of each excerpt. The students' intonations heighten which portrayed lack of confidence, as they appeared to seek for the interviewer's evaluation and assurance to their responses. These students are from the average and below average levels of ability. Therefore, seeking for instructor's assurances if one-to-one guidance is provided may be a norm to them before attempting to solve the word problems.

Interview responses to Question 3: Tell me how you are going to find the answer and Question 4: Show me what to do to get the answer. Talk aloud as you do it, so that I can understand how you 
are thinking. The interview responses to Question 3 and Question 4 were analysed and classified into themes as follows.

\begin{tabular}{|l|c|}
\hline Theme & Students \\
\hline Theme 1: Students who implemented the Hybrid Strategy and arrived at correct answers & S2, S29 \\
\hline Theme 2: Students who implemented the Hybrid Strategy but arrived at incorrect answers & S39 \\
\hline Theme 3: Students who did not implement the Hybrid Strategy and arrived at correct answers & S3, S21, S22, S40 \\
\hline Theme 4: Students who did not implement the Hybrid Strategy but arrived at incorrect answers & S4, S16, S8, S14 \\
\hline
\end{tabular}

Table 5. Classification of themes for interview responses to Questions 3 and 4

Amongst the 11 selected students for interviews, only 3 students were implementing the Hybrid Strategy during their interview sessions with one exceptional case of obtaining incorrect answer as seen in Table 5. The following interview excerpts showed the students' verbal and written responses to Questions 3 and 4 of the interviews.

\begin{tabular}{|l|l|}
\hline Speaker & Questions and Responses \\
\hline Interviewer & Uhh tell me how you are going to find the answer \\
\hline S2 & Mmm we plus \\
\hline Interviewer & Ok..? \\
\hline S2 & We plus 1820 plus 1 hour 25 min, then we plus the total, with 5 hours \\
\hline Interviewer & $\begin{array}{l}\text { Ok show me what to do to get the answer. [Students running and shouting outside] Talk aloud as } \\
\text { you do it, so that I can understand how you are thinking. You can use a [inaudible] }\end{array}$ \\
\hline S2 & $\begin{array}{l}\text { So here we use the } 4 \text { Warriors, first write down the } 4 \text { Warriors and Mr. How. [S2 starts to write] First, } \\
\text { who... what... where... and when, the } 4 \text { Warriors. So.. next will be Mr. How. First we answer the } \\
4 \text { Warriors, we answer who, no person. What is RBA... So.. Where, BSB... Singapore... and } \\
\text { Australia... so after this so when, when is } 1820 \text { hours... } 1 \text { hour } 25 \text { min.... and } 5 \text { hours. Then you } \\
\text { draw what you understand here for example, here we draw BSB, here is Singapore... and then, just } \\
\text { draw the, how the flight goes over here, the flight RBA [inaudible] } 1 \text { hour } 25 \text { min. So then will be } \\
\text { Australia... and then the flight will go to Australia like this and over here is the plane, which is } \\
5 \text { hours, and then we help Mr. How, which is addition.... } \\
\text { Bracket, it is } 1820 \text { plus } 1 \text { hour } 25 \text { min and then plus } 5 \text { hours... we do the working over here with the } \\
\text { specific addition of time. We have different sections. Two sections for hour and minute. It was } \\
1 \text { hour } 25 \text { min like this and then just like this } 5 \text { and then } 5 \text {, here will be separated and then } 9 \text {, and } \\
\text { then another } 1, \text { which is } 1955 \text { hours. So equals } 1955 \text { hours, plus } 5 \text { hours, so equal to plus } 500 \text { and } \\
\text { then here will be } 55 \text { min, and then this will be.... } 14 \text { and over here so there's } 24, \text { which is } 0055 . \text { So } \\
\text { arrived at } 0055 \text { hours. }\end{array}$ \\
\hline
\end{tabular}

Table 6. Interview excerpts from student S2

\begin{tabular}{|l|l|}
\hline Speaker & Questions and Responses \\
\hline Interviewer & $\begin{array}{l}\text { Ok, can you uhh show me, can you write it down here, uhh show me your working and then can you } \\
\text { talk while doing your working so that I know what you are doing }\end{array}$ \\
\hline S29 & {$[$ S29 starts writing $]$} \\
\hline Interviewer & $\begin{array}{l}{[\text { After } 1 \text { minute and } 4 \text { seconds] ok, so what are we doing now? [S29 continues writing] [After }} \\
20 \text { seconds] uhh, is that your final answer? }\end{array}$ \\
\hline S29 & {$[\mathrm{S} 29$ nodding head] } \\
\hline
\end{tabular}

Table 7. Interview excerpts from student S29

Student S2 and S29 who were from the above average level of ability were the only students who implemented the Hybrid Strategy and arrived at the desired solutions. With regards to the interview excerpts from Student S2 (see Table 6), the student was able to explicitly explain the steps involved in the Hybrid Strategy verbally while solving the problem. The student was also able to narrate the problem as a story situation in the question while drawing, indicating that the student was able to perceive the word problem as a story to be completed with the help of the Hybrid Strategy. 
Student S29 however did not provide verbal explanations of his implementation of the Hybrid Strategy nor did he generate drawings during the interview. However, the student was observed to have been able to carry out the strategy without displaying signs of uncertainty. This indicates that the student had fully comprehended the word problem presented despite his implementation of the strategy.

\begin{tabular}{|l|l|}
\hline Speaker & Questions and Responses \\
\hline Interviewer & Ok, tell me how you're going to find the answer \\
\hline S39 & Umm, 9 plus 3 \\
\hline Interviewer & $\begin{array}{l}\text { Ok.. 9 plus 3. Can you show me your working and while you are showing your working, can you just } \\
\text { talk? So that I know what you are doing. }\end{array}$ \\
\hline S39 & {$[$ S39 starts writing $]$ 9.. uhb buat working kah? (Do I do the working?) } \\
\hline Interviewer & Yes \\
\hline S39 & {$[$ S39 starts writing silently, and after 13 seconds] 12.. } \\
\hline Interviewer & Ok, uhh so is that your answer? \\
\hline S39 & Uhh yeah \\
\hline
\end{tabular}

Table 8. Interview excerpts from student S39

Interview excerpts and working solution extracted from Student S39 (see Table 8) who was from below average level of ability show that the student was able to carry out the steps in the Hybrid Strategy correctly but was unable to obtain the required answer. This particular student displayed understanding of the strategy but was still having difficulties in comprehending the word problem itself. This further proved that the student was still practicing the usual rote learning over conceptual and meaningful understanding (Pungut \& Shahrill, 2014; Rokhimah, Suyitno \& Sukestiyarno, 2015). Therefore, for this reason, the student's use of the Hybrid Strategy may have not lent her much support in comprehending the word problem. According to Table 4 during the interview sessions, there were 4 students who did not implement the Hybrid Strategy but arrived at correct answers. These students were able to solve the word problems posed correctly using their own preferred methods. However, there were also 4 students who did not implement the Hybrid Strategy but arrived at incorrect answers. These students were from average and below average levels of ability.

\begin{tabular}{|l|l|}
\hline Speaker & Questions and Responses \\
\hline Interviewer & $\begin{array}{l}\text { All right, show me what to do to get the answer, talk aloud as you do it so that I can understand how } \\
\text { you are thinking. }\end{array}$ \\
\hline S4 & Buat macam who atu cikgu? (Do it like the 'who..') \\
\hline Interviewer & It's up to you. \\
\hline S4 & Tani mesti macam, kan 3 buku.. (we have to like, there are 3 books) \\
\hline Interviewer & Ok, can you write it down while you are talking and doing your working? Can you show me? \\
\hline S4 & $\begin{array}{l}\text { [S4 starts writing] macam ani } 3 \text { books, ia macam mau altogether ani berapa (Like here there are } 3 \text { books, the } \\
\text { question wants how much is } 3 \text { books) Lapas atu kitani mesti plus.. } 12 \text { atu semua jumlab } 3 \text { ani, } 12 \text { (and } \\
\text { then we have to plus.. } 12 \text { is the total of the three, 12) }\end{array}$ \\
\hline
\end{tabular}

Table 9. Interview excerpts from student S4

The similarity between interview excerpts from the above students who did not use the Hybrid Strategy during the interview and were still unable to arrive at correct answers is that these students appeared to be confident with their responses. For instance, from the interview excerpts from Student S8 (see Table 11), the interviewer purposely asked if the student was sure of his final answer. The student instantly responded with 'yeah', portraying a firm gesture indicating his determination of his final answer. Furthermore, the students also appeared to instantly assume the correct mathematical operation(s) for the word problem without first constructing sufficient understanding of the question. This type of Comprehension error is evident in interview excerpts of Student S14 (see Table 12), the student immediately 
assume 'multiplication' because of the word 'identical'. The student's mere assumption could be based on the type of input he received during lessons; whenever the word 'identical' is encountered; he means the increase in quantity of an object. Although the students did not practice the use of the Hybrid Strategy during the interviews, Student S4 and Student S16 who were from below average level of ability have demonstrated a slight shift in their perceptions towards the word problems posed, however limited. For example, in Table 8, the way in which Student S4 responded reflects his views of the problem as a story situation. He explicitly explained the requirement of the question 'macam ani 3 books, ia macam man altogether ani berapa (Like here there are 3 books, the question wants how much is 3 books)', which reflects his understanding of the question. However, Student S4 was unable to transform the word problem into mathematical representation, hence chose incorrect mathematical operation to perform. This type of error is identified as Transformation error.

\begin{tabular}{|l|l|}
\hline Speaker & Questions and Responses \\
\hline S16 & Ia tanya berapa semua apples atu (it is asking how many apples are there) \\
\hline Interviewer & $\begin{array}{l}\text { Ok, uhh bagitau cikgu cemana cara-cara S16 kan menjawab soalan ani (tell me how you are going to } \\
\text { answer the question) }\end{array}$ \\
\hline S16 & $\ldots \ldots$ divide \\
\hline Interviewer & $\begin{array}{l}\text { Divide? Ok, cuba lihatkan teacher your working here (Try to show me your working here) while S16 } \\
\text { buat your working, cuba bagitahu teacher what you are doing (while you are doing your working, try } \\
\text { to tell me what you are doing) }\end{array}$ \\
\hline S16 & {$[$ S16 starts writing $]$} \\
\hline Interviewer & Ok, so dua puluh divide by? Seven (so twenty divide by? Seven) \\
\hline S16 & {$[$ S16 writing $]$} \\
\hline Interviewer & {$[$ After 12 seconds] Ok S16, cuba baca soalan lagi (Ok S16, try to read the question again) } \\
\hline
\end{tabular}

Table 10. Interview excerpts from student S16

\begin{tabular}{|l|l|}
\hline Speaker & Questions and Responses \\
\hline Interviewer & $\begin{array}{l}\text { Divide? Ok, can you show me how to get the answer? And while you are doing your working, can } \\
\text { you... Umm talk so that I know what you are doing. Ok. }\end{array}$ \\
\hline S8 & [Starts writing but the pencil is not working] \\
\hline Interviewer & Uhh you can use this \\
\hline S8 & [Starts writing] [naudible] here, 6 minus 6, so 1. \\
\hline Interviewer & Are you sure is that you answer? \\
\hline S8 & Yeah \\
\hline
\end{tabular}

Table 11. Interview excerpts from student S8

The analyses of interview responses to Question 3 and Question 4 above showed that the above average students were able to apply and understand the steps involved in the Hybrid Strategy without fault and one of them appeared to have perceived word problem as story problem with the use of the strategy. However, one student from below average level of ability demonstrated her procedural understanding of the Hybrid Strategy only, thus was unable to solve the problem correctly. Students who did not implement the Hybrid Strategy yet arrived at incorrect solutions during the interviews displayed Comprehension errors; particularly in assuming the correct mathematical operation(s) for the problem without first having true understanding and they did so with confidence. However, below average students such as Student S4 and Student S16 demonstrated their slight change in perceptions towards mathematical word problems when solving but was unable to solve them correctly due to committing Transformation errors. Therefore, based on the analyses of students' responses during the interviews, it can be deduced that the use of Hybrid Strategy may have helped the students in perceiving word problems as story problem particularly students who were from below average level of ability. However, due to persistent Comprehension and Transformation errors exhibited by the students during the interviews, some of the students were unable to solve the word problems correctly. 


\begin{tabular}{|l|l|}
\hline Speaker & Questions and Responses \\
\hline Interviewer & $\begin{array}{l}\text { All right, uhh can you show me how to get the answer? While you are doing your working uhh } \\
\text { talk, so that I know what you are doing. Ok? You can do your working. }\end{array}$ \\
\hline S14 & {$[$ S14 starts writing $]$} \\
\hline Interviewer & {$[$ After 22 seconds of S14 writing] Ok, so what are you doing now? } \\
\hline S14 & Minus \\
\hline Interviewer & Ok, what do you minus? \\
\hline S14 & $\$ 50$ minus $\$ 29$ \\
\hline Interviewer & All right Ok and then? \\
\hline S14 & {$[$ S14 starts writing] } \\
\hline Interviewer & {$[$ After 26 seconds of S14 writing] Ok now write down your answer to the question. } \\
\hline S14 & {$[$ S14 writes down answer] } \\
\hline Interviewer & Ok, tell me what do you do here? \\
\hline S14 & 21 times 7 \\
\hline Interviewer & Mhmm. Why do you times $7 ?$ \\
\hline S14 & {$[$ After 12 seconds of silence] because... Amirul bought 7 identical plates } \\
\hline
\end{tabular}

Table 12. Interview excerpts from student S14

Interview responses to Question 6: Do you think by drawing a picture will make you understand the question better? And Question 7: Would you prefer drawing a picture before trying to solve the problem? Majority of the students believed that drawing pictures would make them understand word problems better and preferred to generate drawings before attempting to solve word problems.

Interview responses to Question 8: Would you use the Hybrid Strategy: Mr. How and his 4 Warriors and drawing pictures I taught you the other day? All of the students interviewed claimed that they would use the Hybrid Strategy when encountered with word problems hereafter. However, when probed, 3 of the students were still unable to attain the answers to the problems using the strategy. This proved that the students were still struggling in comprehending the word problems, despite the implementation of the strategy.

Therefore, the analyses from students' written responses of the pre- and post-tests, and the interview transcripts of 11 selected students proved that they all committed all five types of error as identified by Newman (1977). Analyses showed that the most common type of error students tended to exhibit was Comprehension errors, particularly Number grabbing and assumptions of mathematical operation(s) without first having sufficient understanding. This result coincides with findings obtained by Yusof and Langkan (2016) on their case study of Year 5 students in solving word problems involving Fractions. However, the percentage means of Comprehension and Transformation errors decrease after intervention lessons where the Hybrid Strategy was introduced to the students. Therefore, this indicates that the use of the Hybrid Strategy in minimising Comprehension and Transformation errors was successful. However, other errors such as Process skills, Encoding, No working and/or no answer and Incomplete emerged with high percentage means causing students' overall achievement to decrease in the post-test. The use of the Hybrid Strategy during intervention lessons had a slight impact on the average and below average students' performance in solving word problems particularly in their perceptions towards mathematical word problems. However, majority of them showed a degree of procedural understanding of the Hybrid Strategy only. This is the result of students' early impressions that Mathematics can be easily dealt with mere memorising of steps and procedures, supporting the belief findings from Pungut and Shahrill (2014). Therefore, conceptual understanding of implementing the strategy to aid their true understanding in solving word problems in this study remains questionable.

In terms of finding the extent of Year 5 students' performances in improving their skills in solving word problems after intervention lessons on the use of hybrid strategy, the total scores obtained from 
the pre- and post-tests of the participants were recorded on a spreadsheet, which was then further examined. Field notes from general observations during the intervention lessons were also analysed and extracted. A Wilcoxon signed-rank test for students' overall performance was employed to determine whether the two means of the pre- and post-tests are significantly different in terms of the students' overall scores in the post-test as compared to the pre-test. It is also to further support and verifies the results produced by the spreadsheet in finding out any significant improvement between the pre-test and the post-test.

\subsection{Results from the Implementation of the Hybrid Strategy in the Post-Test}

The results from using the spreadsheet concluded that students performed better in the pre-test compared to the post-test with only 6 out of 39 students who made improvements in their total scores. Further analysis of students' written responses from the pre- and post-tests revealed that only 3 out of 6 students who improved in their performance have implemented the Hybrid Strategy in their post-test. Such improvements in total marks of the post-test are shown in Table 13.

\begin{tabular}{|c|c|r|r|}
\hline Student ID & Level of Ability & Total Marks in Pre-Test & Total Marks in Post-Test \\
\hline S18 & Average & 9 & 13 \\
\hline S19 & Below average & 5 & 6 \\
\hline S28 & Above average & 16 & 17 \\
\hline
\end{tabular}

Table 13. Students who improved in their post-test

Table 13 shows a significant improvement in scores of Student S18 who was from average level of ability. Further analysis on Student S18's written responses of the post-test revealed that along with implementing the Hybrid Strategy, she also had highlighted keywords and numerical figures in the word problems by drawing boxes around them which might have further helped her to comprehend the requirement of the questions and thus chose the appropriate mathematical operation(s). Fine details on students' variations of diagrams reflect even more clearly of the students' understanding of the word problems (Cheng, 2015). As for Student S19 and Student S28 however, there was no significant improvement in their post-test scores as reflected in Table 12. Student S19 who was from below average ability has demonstrated an acceptable level of procedural understanding of the Hybrid Strategy in the post-test. She was able to write the steps in the strategy but unable to transform the word problem into mathematical representation. This further supports the findings obtained previously in this study where students who were from below average level of ability tend to exhibit procedural understanding of the strategy only but unable to truly solve and comprehend the problem situations. Therefore, the written responses by Student S19 were found not associated with sufficient understanding. Thus, were still considered as Comprehension errors. Whereas written responses of Student S28 who was from above average ability showed a number of Process skills errors in which the student had carried out incorrect computations of desired mathematical operation(s) in the word problems despite his application of the Hybrid Strategy. This type of error contributed to Student S28's insignificant improvement in his post-test scores. Therefore, this indicates that despite the use of the Hybrid Strategy in the post-test, errors such as Process skills errors and mere procedural understanding of the strategy may prevent the students from making significant improvements in their ability to solve mathematical word problems. Further analysis was conducted on students' ways of implementing the Hybrid Strategy in their post-test. The patterns from students' written responses of their post-test were first looked at followed by categorising the patterns as shown in Table 14 . 


\begin{tabular}{|l|r|}
\hline Category & Total No. of students (N=39) \\
\hline Implement Hybrid Strategy & 29 \\
\hline Did not implement Hybrid Strategy & 10 \\
\hline Inconsistent implementation of Hybrid Strategy & 2 \\
\hline Omitting Step 3 (drawing/sketching) of the Hybrid Strategy & 8 \\
\hline
\end{tabular}

Table 14. Details of students' implementation of the Hybrid Strategy

From Table 14, more than half of the students (29 out of 39 students) have implemented the Hybrid Strategy in the post-test. However, 8 out of 29 students were found to have omitted Step 3 of the Hybrid Strategy, which required the students to visualise their understanding of the problem situations via drawing or sketching. During intervention lessons, some students were constantly enquiring if it was necessary for them to carry out Step 3 (drawing/sketching) of the Hybrid Strategy. In addition, some students who were called upon to share their workings using the Hybrid Strategy with the whole class were observed to be hesitant when it comes to drawing or sketching despite constant reminders for the students that they were not required to draw or sketch precisely and beautifully. Students' avoidance towards Step 3 of the Hybrid Strategy may be caused by their lack of confidence and poor self-image towards their ability to draw or sketch, thus they have become very resistant to adapt to the method. Hence, eventually, the students were unable to realise the importance of using visual representations in lending support when solving word problems.

According to Table 14, 2 out of 29 students who implemented the Hybrid Strategy demonstrated inconsistency in using the strategy during their post-test. These students appeared to have practiced the Hybrid Strategy in some questions in the post-test only. A possible explanation for this is that they may still be experimenting their preferences of methods when solving word problems. The close examinations of improved students' written responses and students' ways of implementing the Hybrid Strategy suggested that the effectiveness of the strategy in improving students' ability in solving word problems remains questionable. Thus, the employment of statistical tests will further verify the effect of the intervention lessons using the Hybrid Strategy towards students' ability performance in solving word problems.

\subsection{Overall Achievements Between the Pre- and Post-Tests}

The data collected from the pre- and post-test scores were first tested for normality using SPSS Version 23. First, the Z-values of the Skewness and Kurtosis of pre-test and post-test scores were computed. All four of the Z-values are within \pm 1.96 . Thus, it can be concluded that the data are slightly skewed and kurtosis for both pre-test and post-test scores. Nonetheless, they do not differ significantly from normality. Hence, it can be assumed that the data are approximately normally distributed, in terms of Skewness and Kurtosis. To further confirm the normality of the data collected, statistical figures obtained from the Shapiro-Wilk test were analysed. The analysis revealed that the frequency distribution of the pre-test scores was not approximately distributed. Therefore, the data collected for this study is not normally distributed. Hence, for this reason, Wilcoxon Signed-rank test was employed to test if there is a significant difference between the scores of the pre-test and the post-test. As for the Wilcoxon signed-rank test, according to the descriptive statistics obtained for the study (see Table 15), the mean of the pre-test scores is higher than the mean of the post-test scores. The overall performance of the students showed that there was a decrease in the achievement of the post-test as compared to the pre-test.

\begin{tabular}{|c|c|c|c|c|c|}
\hline & $\mathbf{N}$ & Mean & Std. Deviation & Minimum & Maximum \\
\hline Pre-Test & 39 & 13.3333 & 6.92187 & 2.00 & 25.00 \\
\hline Post-Test & 39 & 10.2564 & 6.09451 & .00 & 23.00 \\
\hline
\end{tabular}

Table 15. Descriptive statistics of the pre- and the post-tests 
SPSS Version 23 software also provided the number of participants who have negative and positive ranks and ties in the study as shown in Table 15. The ranks show that there were 26 cases where the total scores of the post-test are lower than the total scores of the pre-test and there were only 6 cases where the total scores of the post-test are higher than that of the pre-test. This further validates the results recorded using the spreadsheet.

\begin{tabular}{|c|c|c|c|c|}
\hline & & $\mathbf{N}$ & Mean Rank & Sum of Ranks \\
\hline \multirow{4}{*}{ Post-Test - Pre-Test } & Negative Ranks & $26^{a}$ & 18.65 & 485.00 \\
\hline & Positive Ranks & $6^{\mathrm{b}}$ & 7.17 & 43.00 \\
\hline & Ties & $7^{c}$ & & \\
\hline & Total & 39 & & \\
\hline
\end{tabular}

Table 16. Details of ranks of pre- and post-test scores

Therefore, the results obtained from the descriptive statistics (see Table 15) and the ranks (see Table 16) verify that the students performed better in the pre-test as compared to the post-test. The Wilcoxon signed-rank test further determines the significance of the results obtained for this study as illustrated in Table 17.

\begin{tabular}{|l|r|}
\hline & \multicolumn{1}{|c|}{ Post-test - Pre-test } \\
\hline$Z$ & $-4.142^{\mathrm{b}}$ \\
\hline Asymp. Sig. (2-tailed) & .000 \\
\hline
\end{tabular}

Table 17. Wilcoxon signed-rank tests statistics

The Wilcoxon signed- rank test showed that there was a significant difference in mean scores for the pre-test $(\mathrm{M}=13.33, \mathrm{SD}=6.92)$ and the post-test $(\mathrm{M}=10.26, \mathrm{SD}=6.09)$, with $\mathrm{Z}=-4.142, \mathrm{p}<0.001$, with a large effect size of 0.66 , computed by Cohen's d classification of effect sizes. The direction of the difference is that the students' achievements decreased as measured by the post-test when compared to as measured by the pre-test. Therefore, the overall analysis and statistical tests of students' scores in their pre-test and post-test indicate that the students' performed better in the pre-test as compared to the post-test. Hence, it can be concluded that there was no significant improvements in students' performance in solving word problems after the intervention lessons involving the use of the Hybrid Strategy. This could be due to insufficient amount of practices and exposures provided for the students in using the Hybrid Strategy before the post-test. However, there still exist small number of cases where students made improvements in their post-test performances. There were only 6 students who improved in their post-test scores. Out of these 6 students, only 3 students who implemented the Hybrid Strategy in their post-test. Therefore, despite the small number of students who improved in their post-test using the Hybrid Strategy, it can be deduced that the intervention lessons where the Hybrid Strategy was introduced in the study were only effective to a certain extent.

\section{Conclusions}

Students' difficulties in solving mathematical word problems have been one of the main areas of research focus locally and across the globe. Generally, the study revealed that students mostly commit Comprehension errors, which was due to students' tendency to carry out Number grabbing and assumptions of correct mathematical operation(s) required to solve the word problems. These types of error ought to be diagnosed at an early stage to avoid such errors from developing further. The employment of the Hybrid Strategy in minimising Comprehension and Transformation errors was proven successful by analyses carried out in this study. Students' improvement in their understanding and perceptions towards mathematical word problems using the Hybrid Strategy was only effective to a certain extent. Therefore, the results and findings obtained in this study may serve as a starting point to the body of existing literature where future 
researchers and teachers are encouraged to revise and re-formulate the intervention strategy in diagnosing particularly other errors committed by students when solving word problems.

In conclusion, a number of local and worldwide researchers and teachers have been proposing and executing alternative strategies to improve students' competency in solving mathematical word problems. However, there is a need in fostering the growth of students' positive perceptions towards Mathematical word problems in order to sustain as minimum errors as possible.

\section{Recommendations for Further Research}

The study investigates the effectiveness of the Hybrid Strategy in minimising Comprehension and Transformation errors. It is also to improve students' understanding of the processes involved in solving word problems and students' perceptions towards mathematical word problems. The main focus of this study is the use of visual representations and interrogative words (who, what, where, when and how) in prompting students' understanding and helping them to view word problems as story problems. For further research, it would be useful to revise and improve the strategy particularly in addressing other errors apart from Comprehension and Transformation errors in helping students make significant improvements in their word problem solving skills. It would also be useful to explore other methods related to perceiving word problems as story problems from different standpoints. For instance, using hands-on teaching aids such as manipulatives and props and having the students to physically 'act out' the word problems during lessons which may help in developing strong mathematical conceptual foundations in students in preparations for more advance Mathematics (TESS, 2017).

This study was conducted at the Primary school level. It is recommended that further studies could be worthwhile if longitudinal studies on solving mathematical word problems could be conducted in other Brunei classrooms as issues related to solving word problems are seen as an on-going phenomenon. Through longitudinal studies, longer period of intervention lessons could be conducted thus allowing the intervention strategies to be more effective and sustainable.

\section{Declaration of Conflicting Interests}

The authors declared no potential conflicts of interest with respect to the research, authorship, and/or publication of this article.

\section{Funding}

The authors received no financial support for the research, authorship, and/or publication of this article.

\section{References}

Abdullah, N., Shahrill, M., Tan, A., \& Yusof, J. (2017). Comparing students' level of conceptual understanding and procedural skills when solving non-routine problems. Information-An International Interdisciplinary Journal, 20(10A), 7117-7124.

Abdullah, N.A., Shahrill, M., Yusof, J., \& Prahmana, R.C.I. (2018). Identifying the factors affecting students' performances in primary school mathematics. Journal of Physics: Conference Series. 1097(1), 012137. IOP Publishing. https://doi.org/10.1088/1742-6596/1097/1/012137

Baroudi, Z. (2006). Easing students' transition to algebra. Australian Mathematics Teacher, 62(2), 28-33.

Cheng, L.P. (2015). Error Analysis for Arithmetic Word Problems - A Case Study of Primary Three Students in One Singapore School. National Institute of Education, Singapore. International Journal for Mathematics Teaching and Learning, 1-27.

Chong, M.S.F., Shahrill, M., \& Li, H.C. (2019). The integration of a problem solving framework for Brunei high school mathematics curriculum in increasing student's affective competency. Journal on Mathematics Education, 10(2), 215-228. https://doi.org/10.22342/jme.10.2.7265.215-228 
Chong, M.S.F., Shahrill, M., Putri, R.I.I., \& Zulkardi. (2018). Teaching problem solving using non-routine tasks. AIP Conference Proceedings, 1952(1),020020. AIP Publishing. https://doi.org/10.1063/1.5031982

Gebremichael, A.T. (2014). Students' Perceptions about the Relevance of Mathematics to Other School Subjects. Kristiansand, Norway: Universitetet i Agder, Department of Mathematical Sciences.

Haury, D.L. (2001). Literature-based mathematics in elementary school. ERIC Clearinghouse for Science, Mathematics, and Environmental Education.

Hong, H. (1996). Effects of mathematics learning through children's literature on math achievement and dispositional outcomes. Early childhood research quarterly, 11(4), 477-494. https://doi.org/10.1016/S08852006(96)90018-6

Kingsdorf, S., \& Krawec, J. (2016). A broad look at the literature on math word problem-solving interventions for third graders. Cogent Education, 3(1), 1135770.

https://doi.org/10.1080/2331186X.2015.1135770

Mills, G.E. (2014). Action Research: A Guide for the Teacher Researcher. New Jersey: Prentice-Hall Inc.

Murphy, S.J. (2000). Children's Books about Math: Trade Books That Teach. New Advocate, 13(4), 365-374.

Newman, M.A. (1977). An analysis of sixth-grade pupils' errors on written mathematical tasks. Victorian Institute for Educational Research Bulletin, 39, 31-43.

Newman, M.A. (1983). Strategies for Diagnosis and Remediation. Sydney, Australia: Harcourt Brace Jovanovich.

Pungut M.H.A., \& Shahrill, M. (2014). Students' English language abilities in solving mathematics word problems. Mathematics Education Trends and Research, [Online] 1-11. https://doi.org/10.5899/2014/metr00048

Rokhimah, S., Suyitno, A., \& Sukestiyarno, Y.L. (2015). Students error analysis in solving math word problems of social arithmetic material for 7 th grade based on Newman procedure. Proceeding in International Conference on Conservation for Better Life, 349-356.

Rosney, Z. (2008). Lower Secondary Teachers' Beliefs about Mathematics Teaching and Learning. Master Dissertation. Brunei Darussalam: Universiti Brunei Darussalam.

Sajadi, M., Amiripour, P., \& Malkhalifeh, M.R. (2013). The examining mathematical word problems solving ability under efficient representation aspect. Mathematics Education Trends and Research, 2013, 1-11. https://doi.org/10.5899/2013/metr-00007

Sakdiah, L. (2008). Research in Mathematics Teaching in Brunei Darussalam. Master Dissertation Brunei Darussalam: Universiti Brunei Darussalam.

Saman, A., \& Suffolk, J. (2001). Investigating Understanding by Primary 6 Pupils of Word Problems involving Multiplication and Division. Sixth Annual International Conference on Science, Mathematics and Technological Education. Universiti Brunei Darussalam, Brunei Darussalam.

Schiro, M. (2004). Oral Storytelling and Teaching Mathematics: Pedagogical and Multicultural Perspectives. California: SAGE Publications. https://doi.org/10.4135/9781452229751

Shahrill, M. (2009). From the General to the Particular: Connecting International Classroom Research to Four Classrooms in Brunei Darussalam. Doctoral Dissertation. Melbourne, Australia: University of Melbourne.

Shahrill, M. (2018). Teachers' devotion to review lessons: Insights to the mathematics lessons in Brunei Darussalam. Journal of Physics: Conference Series. 1028(1), 012158. IOP Publishing. https://doi.org/10.1088/1742-6596/1028/1/012158

Shahrill, M., \& Clarke, D.J. (2019). Pedagogical features that influence mathematics classroom practices - A Bruneian perspective. Kasetsart Journal of Social Sciences, 40(2), 341-348. 
Shahrill, M., \& Prahmana, R.C.I. (2018). The connection commonalities in the mathematical content of lesson sequences. Journal of Physics: Conference Series. 1097(1), 012136. IOP Publishing. https://doi.org/10.1088/1742-6596/1097/1/012136

Shahrill, M., Prahmana, R.C.I., \& Roslan, R. (2018). The relationships within the mathematical content of teachers' lesson sequences. Journal of Physics: Conference Series. 943(1), 012001. IOP Publishing. https://doi.org/10.1088/1742-6596/943/1/012001

Shahrill, M. Putri, R.I.I., Zulkardi, \& Prahmana, R.C.I. (2018). Processes involved in solving mathematical problems. AIP Conference Proceedings. 1952(1), 020019. AIP Publishing. https://doi.org/10.1063/1.5031981

Teacher Education through School-based Support in India, TESS (2017). Mathematical Stories: Word Problems. The Open University.

Thorton, S., \& Statton, J. (2011). Mathematising and Contextualizing - Connecting Mathematics and Numeracy to Improve Learning for Aboriginal Students. AAMT-MERGA Conference. Alice Springs.

Toor, A., \& Mgombelo, J. (2015). Teaching mathematics through storytelling: Engaging the "being" of a student in mathematics. CERME 9 - Ninth Congress of the European Society for Research in Mathematics Education, Charles University in Prague, Faculty of Education; ERME, Prague, Czech Republic (pp. 3276-3282).

Uesaka, Y., Manalo, E., \& Ichikawa, S. (2007). What kinds of perceptions and daily learning behaviours promote students' use of diagrams in mathematics problem solving? Learning and Instruction, 17, 322-335. https://doi.org/10.1016/j.learninstruc.2007.02.006

Verschaffel, L., Brian, G., \& De Corte, E. (2000). Making Sense of Word Problems. The Netherlands: Swets and Zeitlinger, Lisse.

Welchman-Tischler, R. (1992). How To Use Children's Literature To Teach Mathematics. National Council of Teachers of Mathematics.

White, A.L. (2009). Diagnostic and pedagogical issues with mathematical word problems. Brunei International Journal of Science \& Mathematics Education, 1, 100-112.

Wong, N.Y., Lam, C.C., Wong, K.M.P., Leung, F.K.S., \& Mok, I.A.C. (2001). Students’ views of mathematics learning: a cross-sectional survey in Hong Kong. The Chinese University of Hong Kong. Education Journal, 29(2), 37-59.

Yusof, J. (2003). Mathematical Errors in Fractions Work: A Longitudinal Study of Primary Level Pupils in Brunei. Doctoral Dissertation. Perth, Australia: Curtin University of Technology.

Yusof, J., \& Langkan, J. (2016). Word Problems Involving Fractions: A Case of Year 5 Pupils in Brunei Darussalam. 6th International Conference on Language, Education, and Innovation. Malaysia.

Published by OmniaScience (www.omniascience.com) Journal of Technology and Science Education, 2020 (www.jotse.org)

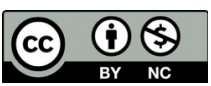

Article's contents are provided on an Attribution-Non Commercial 4.0 Creative commons International License. Readers are allowed to copy, distribute and communicate article's contents, provided the author's and JOTSE journal's names are included. It must not be used for commercial purposes. To see the complete licence contents, please visit https://creativecommons.org/licenses/by-nc/4.0/. 